\title{
Anti-blocking performance of ultrahigh-pressure waterjet assisted furrow opener for no-till seeder
}

\author{
Hongnan Hu, Hongwen Li*, Qingjie Wang, Jin He, Caiyun Lu, Yingbo Wang, Peng Liu \\ (College of Engineering, China Agricultural University, Beijing 100083, China; China Agricultural University National Institute for \\ Conservation Tillage, Beijing 100083, China; Scientific Observing and Experimental Station of Arable Land Conservation (North Hebei), \\ Ministry of Agriculture and Rural Affairs, Beijing 100083, China)
}

\begin{abstract}
No-till planting method is widely used for maize-wheat two-crops-a-year area in the North China Plain. However, cruel soil conditions, especially the large number of maize stalks which are hard to cutoff covering, often cause an unsatisfying planting quality. Based on the authors' previous investigation, ultrahigh-pressure (UHP) waterjet is capable to solve this problem and obtain qualified seedbeds. Thus, a UHP waterjet assisted furrow opener for no-till seeder was designed. Field tests showed that double-disc furrow openers worked well with UHP waterjet, since the sharpened disc blades could help to cut soil and residue, meanwhile, minimize soil disturbance. Response surface method (RSM) was used to investigate the relationship among forward speed, waterjet pressure, jet impingement angle and anti-blocking performance (stalks cutoff ratio and depth of soil cutting), and a Box-Behnken three-factor design was used to identify the optional operation parameters. A total of 17 combinations were conducted, and the results showed all three operation parameters significantly affected anti-blocking performance. Stalks cutoff ratio and depth of soil cutting increased with the increase of waterjet pressure, jet impingement angle, and decreased with the increase of forward speed. The optimization analysis indicated that when waterjet pressure was $267-280 \mathrm{MPa}$, jet impingement angle was $80.2^{\circ}$ to $90.0^{\circ}$ and forward speed was $4.00-4.42 \mathrm{~km} / \mathrm{h}$, the overall performance of UHP waterjet assisted double-disc furrow opener for no-till seeder was maximized. Stalks cutoff ratio could be above $95 \%$ and no blockage occurred. This study may provide a new approach and reference for the anti-blocking technology of no-tillage seeding.
\end{abstract}

Keywords: waterjet, ultrahigh-pressure, conservation tillage, maize stalks, cutting, no-till, anti-blocking DOI: $10.25165 /$ j.ijabe.20201302.5630

Citation: Hu H N, Li H W, Wang Q J, He J, Lu C Y, Wang Y B, et al. Anti-blocking performance of ultrahigh-pressure waterjet assisted furrow opener for no-till seeder. Int J Agric \& Biol Eng, 2020; 13(2): 64-70.

\section{Introduction}

Conservation agriculture plays an important role of sustainable agriculture and soil protection. No-till seeders or planters are intended to working in the field with straw cover, and place seed and fertilizer at the certain depth precisely ${ }^{[1-3]}$. Even though with these sustainable and climate smart advantages, it encounters the problem that when seeding on a no-till field, crop stalks and residue often wind around furrow openers or seeding devices, which makes the no-till seeder cannot work stably. Especially, in the North China Plain two crops (summer maize and winter wheat) are planted in one year, a huge number of maize stalks with high water

\section{Received date: 2020-01-02 Accepted date: 2020-03-20}

Biographies: Hongnan $\mathrm{Hu}, \mathrm{PhD}$ candidate, research interests: conservation agriculture machinery, Email: hongnanhu@qq.com; Qingjie Wang, PhD, Professor, research interests: conservation tillage and equipment. Email: wangqingjie@cau.edu.cn; Jin He, PhD, Professor, research interests: conservation agriculture and farm machine, Email: hejin@cau.edu.cn; Caiyun Lu, PhD, Associate Professor, research interests: precision agriculture technology and equipment, Email: lucaiyun@cau.edu.cn; Email: lhwen@cau.edu.cn; Yingbo Wang, PhD candidate, research interests: conservation agriculture machinery, Email: wangyingbocau@163.com; Peng Liu, $\mathrm{PhD}$ candidate, research interests: conservation agriculture machinery, Email: 1023622964@qq.com.

*Corresponding author: Hongwen $\mathbf{L i}, \mathrm{PhD}$, Professor, research interests: conservation agriculture, agriculture machine and equipment engineering. College of Engineering, China Agricultural University, No.17, Qinghua East Road, Haidian District, Beijing 100083, China. Tel: +86-10-62737300, Email: lhwen@cau.edu.cn. content is produced. The high toughness of these materials is also hard to cutoff or to be cleaned ${ }^{[4]}$. Therefore, no-till seeder for winter wheat should have a good ability of anti-blocking requirement to break through or clean up the maize stalks for anti-blocking requirement.

Currently, the commonly used methods of anti-blocking by cutoff the stalks can be divided into two categories: one is vertical tillage, using heavy coulter to cut crop residue into small pieces ${ }^{[5]}$, which helps to reduce the plugging appearance during the seeding operation. Vertical tillage is recently popular in the United States, Canada and several European countries ${ }^{[6]}$. However, for the maize stalks in two-crop-a-year area, these coulters may not be capable to cut off maize stalks completely. The second is rotary tillage, using high-speed rotary blades to smash maize stalks and then mixing them with top layer soil to create good seedbed conditions $^{[7]}$. High-speed rotary blades can cause soil disturbance and reduce straw cover rate. Meanwhile, both the above soil-engaging tools need very sharp edge and strong wear-resistance, which means strict requirements on manufacturing processes, since the wear of the blades seriously affects the cutting or smashing quality. To avoid these issues, a non-contact cutting method is put forward by using ultrahigh-pressure (UHP) waterjet to cut maize stalks into two pieces then furrow openers follow behind waterjet and accomplish seeding operation.

The technology of high-pressure waterjet has developed rapidly in the past 30 years ${ }^{[8]}$, and widely applied in industrial processing, especially for cutting utilization. With the advancement of high-pressure waterjet generating technology, an 
ultrahigh-pressure waterjet with the waterjet pressure of 280$400 \mathrm{MPa}$ has been developed. After the pure water is pressurized by the ultrahigh-pressure intensifier pump, it is injected from a suitable orifice with the diameter of 0.20-0.4 mm, producing a high velocity water stream (above $1000 \mathrm{~m} / \mathrm{s}$ ) is yielded. Different waterjet operation parameters generate different waterjet velocity, flow rate and kinetic energy, which can be adjusted for various applications such as materials removal, cleaning, cutting, peening, milling, drilling and so on ${ }^{[9]}$. In China, the present application of waterjet technology in agricultural field is mainly focused on cleaning in China. Zhao et al. ${ }^{[10]}$ used continuous non-submerged waterjet to clean granular agricultural products and numerical simulation method was used to study effects of working parameters on clean-up rate. Wang et al. ${ }^{[1-13]}$ used submerged waterjet to clean vegetables, tomatoes and cherries, and studied the limiting factors of cleaning ability. Wang et al. ${ }^{[14]}$ stripped scallops with waterjet, and the optimal working parameters was studied.

The cutting performance of waterjet (depth of cut, amount of material removing, roughness of surface, kerf and taper angle, etc.) has been investigated by the researchers for various materials under different operation parameters (waterjet pressure, water flow rate, orifice diameter, jet impingement angle, standoff distance, traverse speed, etc.). It has been found that operation parameters could significantly influence the outcomes. For the applications in ultrahigh-pressure pure waterjet cutting agricultural materials, depth of cut, in other words, cutoff ratio is the major evaluation criterion of cutting performance. Depth of cut of pure waterjet is mainly affected by waterjet pressure, jet impingement angle, standoff distance, traverse speed ${ }^{[15]}$. Oh et al. ${ }^{[16]}$ investigated waterjet cutting hard rock, and he found that cutting increased with increasing waterjet pressure and decreasing standoff distance; Aydin et al. ${ }^{[17]}$ found that cut depth of granitic rocks increased with increasing waterjet pressure and decreasing traverse speed, and influence from standoff distance was indiscernible, meanwhile, vertical jet impingement angle resulted in higher cut depths than horizontal angle ${ }^{[18]}$; Wang et al. ${ }^{[19]}$ further found that the optimization jet impingement angle for waterjet cutting ceramics and polymer matrix composite was $80^{\circ}$. However, UHP waterjet cutting agricultural materials were rarely studied, and corresponding research of operation parameters need to be conducted for application of agricultural production.

In this study, UHP waterjet assisted furrow opener for no-till seeder was designed to accomplish the high qualified no-till seeding with little soil disturbance and no blockage. The aim of this experimental study was to investigate the coordinate performance of UHP waterjet with different type of furrow openers; figure out the interactions among forward speed, waterjet pressure, jet impingement angle and anti-blocking performance; identify the optimized combination of operation parameters; and serve as a useful basis for future study and practical industry design projects.

\section{Materials and method}

\subsection{Materials}

\subsubsection{Equipment description}

As showed in Figure 1, a prototype of UHP waterjet assisted furrow opener device was designed for use in the fields. It mainly consisted of diesel engine, intensification pump system, hydraulic pump, water pump, electrical control system, water tank, water filter, plumbing, cooling system, cutting head, etc. To ensure this anti-blocking device could continuously work in the field, a diesel engine was used as power source instead of traditional electric motor power source. To be specific, intensifier pump, water pump and electric control system were all driven by the diesel engine. Intensifier pump was one of the most important parts of this device and uses the different area of the plunger to intensify the pressure. The intensification ratio (ratio of plunger area) of this pump was 20. High pressure plumbing could make sure the pure water was transported from intensifier pump to the cutting head safely. The hydraulic oil inside the intensifier pump was provided by the hydraulic pump which was driven by the diesel engine. The rotate speed of the diesel engine was $1500 \mathrm{rpm}$ constantly, and an electronic throttle was used to fix the rotate speed. A total of $130 \mathrm{~L}$ of hydraulic oil circulated in the intensifier pump and cooled in air cooling system. Tap water was stored in the water tank, and when intensification pump system was turned on, tap water was transferred to the water filter by the water pump. Clean filtered water was then pumped into the intensifier pump system, where it was pressurized. Electrically controlled hydraulic valve was used to control the reversing frequency of the pump to adjust waterjet pressure and the waterjet pressure which can be adjusted stepless. Furthermore, an emergency stop was arranged for the security of ultrahigh-pressure operation.

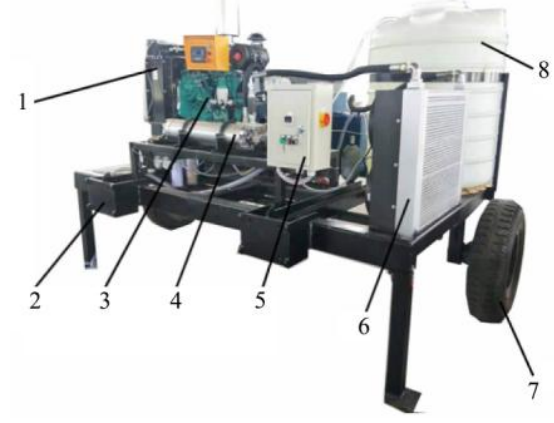

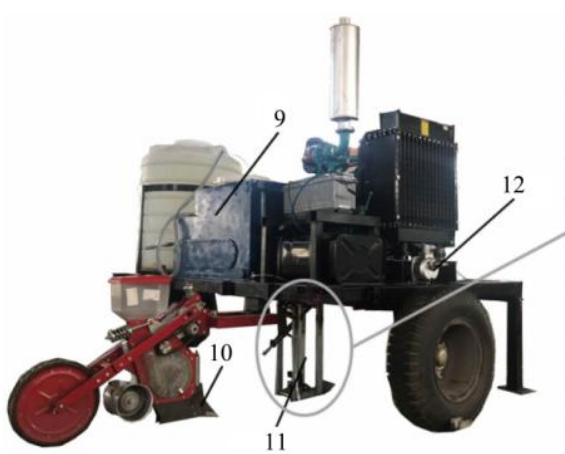

b.

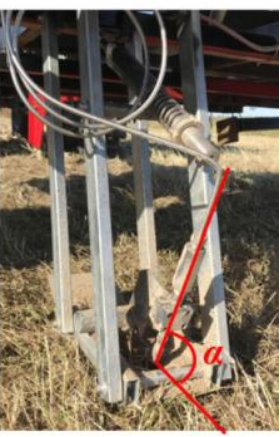

c.
1. Diesel engine cooling system 2. Frame 3. Diesel engine 4. Intensifier pump system 5. Electric control system 6. Air cooling system for hydraulic oil 7. Wheel 8. Water tank 9. Hydraulic oil tank 10. Furrow opener 11. Compaction sliding board for cutting head 12. Water pump $\alpha$ : jet impingement angle

Figure 1 Prototype of ultrahigh-pressure waterjet assisted furrow opener

The cutting head, which is subjected to ultrahigh-pressure inside, was unable to withstand radial force. Considering the working condition of stalks and soil engagement, cutting head needed extra protection compared with indoor work condition. Meantime, the forward waterjet might push the stalks to move along with the cutting head, which is adverse for stalk cutting, so the stalks needed to be immovable during anti-blocking cutting process. Therefore, a compaction sliding board was designed for stalk compaction, ground profiling and cutting head protection. Jet impingement angle also affects the forward push force, so in 
order to achieve angle adjustment the cutting head was hinged on a sliding board and fixed by a lock screw. In this study, jet impingement angle was defined as the angle between the ground horizon plan and cutting head (as showed in Figure 1c), and adjustment range was $30^{\circ}-90^{\circ}$. According to the previous study $^{[20,21]}$, standoff distance should be less than $20 \mathrm{~mm}$ to decrease water steam diffusion and take full advantage of turbulence kinetic energy of waterjet. A parallelogram linkage also was designed to profile the ground and protect the cutting head from crashing soil clods and stubble on the ground. The sliding board was welded at the end of parallelogram linkage and pre-loaded through a pre-loaded spring. The pre-loaded force was adjusted according to the field situation, such as total stalk mass, soil compaction and soil moisture content.

\subsubsection{Field condition}

The field experiment was conducted on September 27, 2019 at

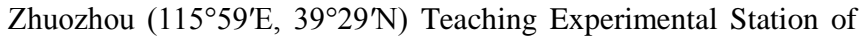
China Agricultural University, Hebei, China. The soil type was sandy loam (USDA classification), and soil moisture content at $0-5 \mathrm{~cm}$ depth was $4.62 \%$. The planting system was two-crop-ayear summer maize and winter wheat. Summer maize (ZhengDan 958) had been harvested and chopped by a combine harvester 8 days before the experiment, and the average moisture content of the maize stalks was $45.48 \%$, the average long axis diameter and short axis diameter of maize stalks were $29.9 \mathrm{~mm}$ and $14.3 \mathrm{~mm}$, respectively. Maize stalk mulching quantity and stalk mulching rate were $1.83 \mathrm{~kg} / \mathrm{m}^{2}$ and $88.13 \%$, respectively. Blocks with $30 \mathrm{~m}$ long and $1 \mathrm{~m}$ wide were selected for each experimental run.

\subsection{Experimental procedure}

\subsubsection{Experiment setup}

Firstly, at the initial exploring stage, a single factor experiment was designed to find out which type of classic no-till furrow opener would match with UHP waterjet assisted furrow opener better; Then, at the optimizing stage, a Box-Behnken design (BBD) was employed to establish the second-order response surfaces for two responses to analyze the relationships between operation parameters and responses (stalks cutoff ratio, depth of soil cutting). Optimization analysis was used to determine the recommended operation parameters; Finally, a confirmation field experiment under the optimization operation parameters was conducted to verify the validity of the optimization results.

In China, the most widely-used types of furrow opener for no-till seeder are hoe opener and double-disc opener. Hoe opener has simple structure, light weight, and lower price, but overlong maize stalks was easy to hang on the shank of hoe opener. While the hoe opener moving forward, the gathering of stalks was growing bigger and would sweep away the neighboring stalks and topsoil with it, and eventually dragged stalks away from the row area. This stalk dragging phenomenon could decrease stalks mulching rate and block the seeding process. Hence, UHP waterjet was arranged in the front of the hoe opener to cut overlong maize stalks into two pieces and let hoe opener go forward through the kerf without hanging stalks. On the other hand, double-disc opener was designed to cut stalks and clods in case of stalk dragging. However, the cutting performance of double-disc opener was poor because the tough and large quantity of summer maize stalks in the North China Plain area, and uncut maize stalks might be pressed into the seedbed by disc and obstruct seeds from falling into soil or even block the following seeding components. It was found that both two types of furrow opener showed the unsatisfactory performance when facing a large amount of tough maize stalks, which was mainly due to the overlong stalks or uncut stalks. Conservation tillage environments required special functions to compensate for little or no tillage to cutoff previous summer maize stalks to loosen the soil $^{[22]}$ prior to the furrow opening operation. In this study, a UHP waterjet was arranged to be the assisted component for maize stalk cutting, and the well-coordinated type of furrow opener was selected by evaluating the values of soil disturbance rate (SDR), stalks cutoff ratio (SCR), depth of soil cutting (DSC) and blockage degree. According to the previous preliminary study ${ }^{[20]}$ and pilot tests, the values of operation parameters of waterjet pressure, jet impingement angle, and forward speed were selected as $260 \mathrm{MPa}, 90^{\circ}$ and $4 \mathrm{~km} / \mathrm{h}$, respectively. Experiment for each type of furrow opener was repeated three times with and without UHP waterjet assist, and the final value was the average of the three repetition measurements.

To investigate the influence of waterjet pressure, jet impingement angle and forward speed on the anti-blocking performance of UHP waterjet assisted the furrow opener were selected at the initial stage. A Box-Behnken three-factor design was also carried out to understand the interactions and optimize the independent variables [waterjet pressure $(P / \mathrm{MPa})$, jet impingement angle $\left(\alpha /^{\circ}\right)$, forward speed $\left(v / \mathrm{km} \cdot \mathrm{h}^{-1}\right)$ ] that affect stalks cutoff ratio (SCR/\%) and depth of soil cutting (DSC/mm). Ranges of each independent variable are showed in Table 1. In total, 17 combinations were conducted, and each combination was repeated for three times. Analysis of variance (ANOVA) was utilized (at 95\% confidence interval) to evaluate the results and Design-Expert V8.0.6 was used to analyze experimental data.

Table 1 Factors with experimental levels for Box-Behnken design

\begin{tabular}{lccccc}
\hline & & & \multicolumn{3}{c}{ Levels } \\
\cline { 4 - 6 } Independent variable & Symbol & Unit & -1 & 0 & +1 \\
\hline Waterjet pressure & $P$ & $\mathrm{MPa}$ & 240 & 60 & 280 \\
Jet impingement angle & $\alpha$ & $\circ$ & 30 & 60 & 90 \\
Forward speed & $v$ & $\mathrm{~km} \cdot \mathrm{h}^{-1}$ & 3 & 4 & 5 \\
\hline
\end{tabular}

\subsubsection{Data collection}

Waterjet pressure was measured by an electrical water pressure sensor (Figure 2a) made by Saipute Electronic Technology Limited Corporation. During the measurements, water pressure sensor was installed at one end of a three-way valve and the water pressure value was showed on a real-time digital display (Figure 2b). Jet impingement angle was measured by protractor, and forward speed was determined according to electronic speedometer of the tractor.

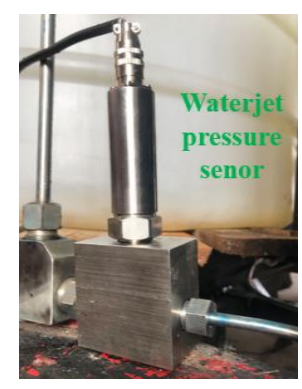

a. Water pressure sensor

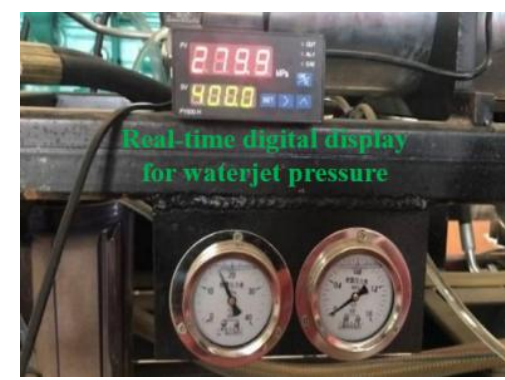

b. Real-time digital display
Figure 2 Water pressure senor with digital display

Stalks cutoff ratio was the ratio of the number of cutoff stalks to the total number of stalks covered on the furrow opening row. During the measurement, three furrow opening rows of $1 \mathrm{~m}$ length were selected randomly from the $20 \mathrm{~m}$ working length of one 
combination, and all the stalks covered on the $1 \mathrm{~m}$ furrow opening row were collected manually and counted. Soil cutoff depth was the furrow depth which was cut by waterjet and the value of soil cutoff depth was the average of the depth of 10 points measured randomly along the furrow opening row. According to GB/T 20865-2017 "no or little tillage fertilizer-seeder" ${ }^{\text {"23] }}$ in China, blockage degree is one of the evaluation index and it is classified into light blockage and heavy blockage. To be specific, during no-till seeding, while light blockage happens, the stalks and residue can flow away smoothly between the rows and seeder works steadily; while heavy blockage happens, stalks and residue wind around the furrow openers or row cleaners tightly, the stalk piles dragging on the ground might cause the lack of power and the seeder cannot work normally. In this study, blockage degree was evaluated for each time of the combinations and was recorded. Meanwhile, soil disturbance rate is another index for no-till seeding, it is the ratio of the soil disturbance width to seeding width. To reduce errors, 6 measurements were randomly taken for each seeding row for one combination. Therefore, soil disturbance rate can be calculated by Equation (1)

$$
D=\frac{\Sigma k_{i}}{6 w} \times 100 \%
$$

where, $D$ is soil disturbance rate; $k_{i}$ is soil disturbance width for each measurement, $\mathrm{mm} ; w$ is seeding width, $\mathrm{mm}$. In this study, seeding width for winter wheat was $150 \mathrm{~mm}$.

\section{Results and discussion}

\subsection{Type selection of furrow opener}

The results of two types of furrow opener coordinate with UHP waterjet was showed in Table 2. It could be seen that UHP waterjet assist improved the performance of both types of furrow opener, moreover, double-disc opener performance better for each of the measured index. The ideal width of furrow trench left by the furrow opener used in this study was equal, which meant they should have the same SDR, however, in this study, SDR of double-disc opener was $9.6 \%$ lower than that of hoe opener (Figures 3d and 3e) because of the better mobility of both double-disc opener and the covered stalks ${ }^{[24]}$. Moreover, openers with UHP waterjet assist ended up with lower SDR than using openers only. UHP waterjet cut off stalks to prevent uncut stalks bringing the topsoil to move along with the seeder and causing higher SDR. Double-disc created lower soil disturbance which meant less soil was thrown out of furrow, more straw covered on the field, less soil moisture loss for seedbed ${ }^{[25]}$ and would make a positive effect on no-till seeding ${ }^{[26]}$.

SCR of double-disc opener with UHP waterjet assist was $15.43 \%$ higher than that of hoe opener, which also promoted high quality seedbed since the seeds had better chance to fall into moist nutrient soil rather than dry stalks. At the same time, the double-disc opener had the cutting ability with its sharpened disc blades, it could cut off the uncut scarfskin next to the topsoil, and increased cutoff ratio. However, for the hoe opener, which could not cut the stalks or soil, only open the soil, the working quality and stability of it mostly depended on the field conditions of stalks length and quantity.

For blockage degree, double-disc opener always performed better than the hoe opener, but with the UHP waterjet assist, the performance of the hoe opener could meet the requirement of national standard for no or little tillage fertilizer-seeder, which required no heavy blockage during the seeding operation. For these above-mentioned reasons, double-disc opener were able to achieve a better coordination with UHP waterjet and further investigation was conducted based on these findings.

Table 2 Outcomes of two types of furrow opener coordinate with UHP waterjet

\begin{tabular}{lcccc}
\hline Type of furrow opener & $\begin{array}{c}\text { Soil } \\
\text { disturbance } \\
\text { rate/\% }\end{array}$ & $\begin{array}{c}\text { Stalks } \\
\text { cutoff } \\
\text { ratio/\% }\end{array}$ & $\begin{array}{c}\text { Depth of } \\
\text { soil cutting } \\
/ \mathrm{mm}\end{array}$ & $\begin{array}{c}\text { Blockage degree } \\
\text { (times for } \\
\text { each run) }\end{array}$ \\
\hline Hoe opener only & $32.5 \pm 3.6$ & 0 & $44.2 \pm 6.3$ & $\begin{array}{c}\text { 2 heavy blocks } \\
\text { and 2 light blocks }\end{array}$ \\
$\begin{array}{l}\text { Hoe opener with UHP } \\
\text { waterjet assist }\end{array}$ & $17.5 \pm 1.9$ & $78.9 \pm 6.3$ & $67.7 \pm 4.7$ & 3 light blocks \\
$\begin{array}{l}\text { Double-disc opener only } \\
\begin{array}{l}\text { Double-disc opener with } \\
\text { UHP waterjet assist }\end{array}\end{array}$ & $14.35 \pm 1.4$ & $94.33 \pm 5.4$ & $75.3 \pm 4.5$ & 0 \\
\hline
\end{tabular}

Note: \pm means standard deviation from the original data

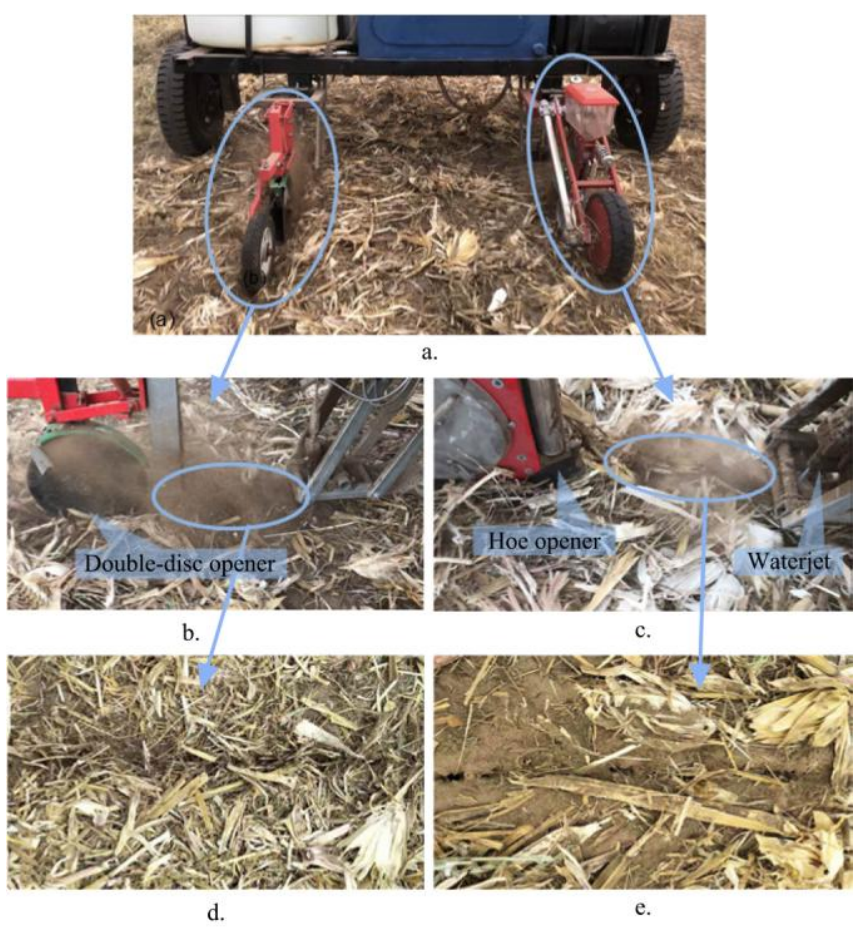

Figure 3 Field experiments for different type of furrow opener coordinate with UHP waterjet

\subsection{Effects of operation parameters on SCR and DSC}

The influences of waterjet pressure, jet impingement angle and forward speed on the SCR and DSC were showed in Table 3. The main effects and interactions were concluded from ANOVA results (Table 4 and Table 5) and the regression model, then the optimized operation parameters were deduced. For both SCR and DSC response, the p-values for lake of fit (LOF) were not significant $(p>0.05)$ and the regression models were extremely significant $(p<0.01)$.

Stalks cutoff ratio was an important indicator for the anti-blocking performance of waterjet assisted furrow opener since the uncut maize stalks seriously obstructed the normal operation of furrow opener. As showed in Table 3 and Table 4, all the operation parameters, waterjet pressure, jet impingement angle and forward speed were extremely significantly $(p<0.01)$ related to stalks cutoff ratio. Interaction between waterjet pressure and jet impingement angle $(P \times \alpha)$ and second-order terms of jet impingement angle $\left(\alpha^{2}\right)$ were significant. Table 5 showed that the "Pred R-Squared" of 0.9601 was in reasonable agreement with the “Adj R-Squared" of 0.9792 (Table 5). The final regression model was given in Equation (2): 


$$
\begin{aligned}
S C R=- & 20.827+0.3338 \times P+1.589 \times \alpha-2.4925 \times v- \\
& 2.9292 \times 10^{-3} \times P \times \alpha-4.4147 \times 10^{-3} \times \alpha^{2}
\end{aligned}
$$

where, $S C R$ is stalks cutoff ratio, \%; $P$ is the waterjet pressure, $\mathrm{MPa} ; \alpha$ is the jet impingement angle, $\left({ }^{\circ}\right) ; v$ is the forward speed of waterjet, $\mathrm{km} / \mathrm{h}$.

Table 3 Box-Behnken experimental matrix and results

\begin{tabular}{ccccccc}
\hline & & \multicolumn{3}{c}{ Factors } & \multicolumn{2}{c}{ Response } \\
\cline { 3 - 7 } Standard & Run & $\begin{array}{c}\text { Waterjet } \\
\text { pressure } \\
/ \mathrm{MPa}\end{array}$ & $\begin{array}{c}\text { Jet } \\
\text { impingement } \\
\left.\text { angle/ } /{ }^{\circ}\right)\end{array}$ & $\begin{array}{c}\text { Forward } \\
\text { speed } \\
/ \mathrm{km}^{-1}{ }^{-1}\end{array}$ & $\begin{array}{c}\text { Stalks } \\
\text { cutoff } \\
\text { ratio/\% }\end{array}$ & $\begin{array}{c}\text { Depth of } \\
\text { soil cutting } \\
/ \mathrm{mm}\end{array}$ \\
\hline 1 & 3 & 240 & 30 & 4 & 71.67 & 34.8 \\
2 & 15 & 280 & 30 & 4 & 82.5 & 69.8 \\
3 & 6 & 240 & 90 & 4 & 92.57 & 64.8 \\
4 & 4 & 280 & 90 & 4 & 96.37 & 88.6 \\
5 & 9 & 240 & 60 & 3 & 88.75 & 45.0 \\
6 & 11 & 280 & 60 & 3 & 93.75 & 82.5 \\
7 & 1 & 240 & 60 & 5 & 84.67 & 40.2 \\
8 & 17 & 280 & 60 & 5 & 90.33 & 68.9 \\
9 & 2 & 260 & 30 & 3 & 80.75 & 60.3 \\
10 & 12 & 260 & 90 & 3 & 97.00 & 88.2 \\
11 & 7 & 260 & 30 & 5 & 72.45 & 56.3 \\
12 & 8 & 260 & 90 & 5 & 92.86 & 63.5 \\
13 & 14 & 260 & 60 & 4 & 90.15 & 65.8 \\
14 & 5 & 260 & 60 & 4 & 90.77 & 66.4 \\
15 & 10 & 260 & 60 & 4 & 89.66 & 62.5 \\
16 & 16 & 260 & 60 & 4 & 89.25 & 70.6 \\
17 & 13 & 260 & 60 & 4 & 90.37 & 68.1 \\
\hline
\end{tabular}

Table 4 ANOVA for response surface reduced quadratic model for stalks cutoff ratio

\begin{tabular}{ccccccc}
\hline Source & $\begin{array}{c}\text { Sum of } \\
\text { squares }\end{array}$ & $d f$ & $\begin{array}{c}\text { Mean } \\
\text { square }\end{array}$ & $F$ value & $\begin{array}{c}p \text {-value } \\
\text { Prob }>F\end{array}$ & \\
\hline Model & 846.6438 & 5 & 169.3288 & 151.3361 & $<0.0001$ & Significant \\
$P$ & 79.948 & 1 & 79.94801 & 71.4529 & $<0.0001$ & \\
$\alpha$ & 637.7806 & 1 & 637.7806 & 570.011 & $<0.0001$ & \\
$v$ & 49.7005 & 1 & 49.7005 & 44.4194 & $<0.0001$ & \\
$P \times \alpha$ & 12.3552 & 1 & 12.3552 & 11.0424 & 0.0068 & \\
$\alpha^{2}$ & 66.8595 & 1 & 66.8595 & 59.7551 & $<0.0001$ & \\
Residual & 12.3078 & 11 & 1.11889 & & & Not \\
Lack of fit & 10.88540972 & 7 & 1.555059 & 4.373055 & 0.0862 & significant \\
Pure error & 1.4224 & 4 & 0.3556 & & & \\
Cor total & 858.9516235 & 16 & & & & \\
\hline
\end{tabular}

Note: This ANOVA result had eliminated the non-effective sources

Table 5 R-Squared values of stalks cutoff ratio statistics analysis

\begin{tabular}{cccc}
\hline Std. Dev. & 1.0578 & $R^{2}$ & 0.9857 \\
\hline Mean & 87.8747 & $\operatorname{Adj} R^{2}$ & 0.9792 \\
C.V. \% & 1.2037 & Pred $R^{2}$ & 0.9601 \\
PRESS & 34.2529 & Adeq Precision & 40.2104 \\
\hline
\end{tabular}

The value of SCR increased with increasing $P$ and $\alpha$, and decreased with increasing $v$. It was mainly caused by the cutting principle of waterjet. As soon as the water stream passes through the nozzle orifice, the waterjet pressure was converted into water velocity, and the kinetic energy of water was the reason of maize stalks cutting. The kinetic energy magnitude of pure waterjet $(E)$ could be theoretically calculated by Equation (3):

$$
E=\frac{t}{2}\left(\dot{m} v_{w}{ }^{2}\right)
$$

where, $E$ is the total kinetic energy of waterjet, $\mathrm{J} ; t$ is the exposure time, $\mathrm{s} ; \dot{m}$ is the time differentiation of water mass; and $v_{w}$ is the water velocity, $\mathrm{m} / \mathrm{s}$. Ignoring the energy loss during the waterjet transmission through the pipe, the pressure potential energy of the outlet of the intensifier pump $\left(E_{p}\right)$ should be equal to the kinetic energy of the outlet of cutting head $\left(E_{c}\right)$. The water velocity $\left(v_{w}\right)$ could be calculated by Equation (4) based on the law of conservation of energy and the Bernoulli's equation:

$$
E_{p}=\frac{P}{\rho}=E_{c}=\frac{\eta v_{m}{ }^{2}}{2}
$$

where, $\rho$ is the density of water, $\mathrm{kg} / \mathrm{m}^{3} ; \eta$ is the correction coefficient of kinetic energy. Substituting $v_{m}{ }^{2}$ from Equation (4) to Equation (3), and the relationship of magnitude kinetic energy of pure waterjet $(E)$ and waterjet pressure $(P)$ and exposure time $(t)$ could be rewritten as:

$$
E=\frac{\dot{m} P t}{\rho \eta}
$$

Higher waterjet pressure generated faster waterjet stream which means higher momentum ${ }^{[27]}$, and more aggressive ${ }^{[16]}$. The waterjet with higher kinetic energy could cut maize stalks deeper ${ }^{[28]}$ with the benefit to increase stalks cutoff ratio. Raising waterjet pressure also improved the cutting efficiency. On the other hand, SCR increased with the increase of $\alpha$. A higher SCR was found when $\alpha$ was $90^{\circ}$, since the cutting head was vertical to the ground, there was no horizontal component force impacting on maize stalks. Horizontal component force which was generated by the waterjet, would push stalks forward rather than cut them off. Meantime, it would reduce the vertical component force which was more effective for stalks cutoff ${ }^{[29]}$. Moreover, if the maize stalks were pushed forward by waterjet as well as the compaction sliding board, the relative exposure time between maize stalks and waterjet steam would be less. It was similar to the faster forward speed caused less exposure time which decreased overlapping energy of waterjet on maize stalks ${ }^{[30]}$. However, to increase the efficiency in practice of agricultural production the forward speed should be as fast as possible, and it would require higher waterjet pressure to compensate the less exposure time caused by smaller $\alpha$ and higher $\alpha$. As showed in Figure 4, when $\alpha$ was $30^{\circ}$, SCR increased greater with the increasing of waterjet pressure compared with $\alpha$ was $90^{\circ}$; Also, when $P$ was $240 \mathrm{MPa}$, SCR increased greater with the increasing of jet impingement angle compared with $P$ was $280 \mathrm{MPa}$

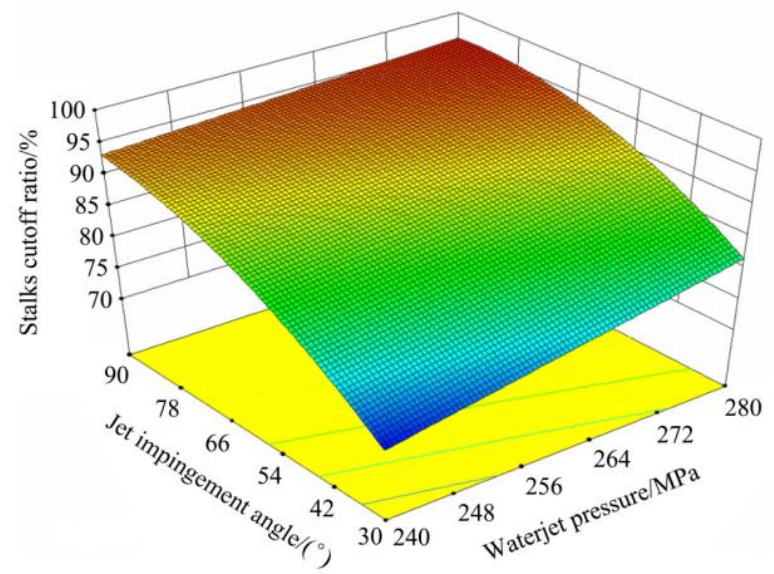

Figure 4 Effects of waterjet pressure and jet impingement angle on stalks cutoff ratio (forward speed $=4 \mathrm{~km} / \mathrm{h}$ ) 
Depth of soil cutting indicated the cutting and penetration ability of waterjet. As shown in Table 3 and Table 6, all the operation parameters, waterjet pressure, jet impingement angle and forward speed were significantly $(p<0.05)$ related to depth of soil cutting. Interaction between jet impingement angle and forward speed $(\alpha \times v)$ and second-order terms of waterjet pressure $\left(P^{2}\right)$ were significant. Table 7 shows the "Pred R-Squared" of 0.8551 was in reasonable agreement with the "Adj R-Squared" of 0.9223 (Table 7). The final regression model was given in Equation (6):

$$
\begin{aligned}
D S C= & -1025.2583+7.321 \times P+1.0396 \times \alpha+4.4625 \times v- \\
& 0.1725 \times \alpha \times v-0.01258 \times P^{2}
\end{aligned}
$$

where, $D S C$ is depth of soil cutting, $\mathrm{mm}$.

Table 6 ANOVA for response surface reduced quadratic model for depth of soil cutting

\begin{tabular}{ccccccc}
\hline Source & $\begin{array}{c}\text { Sum of } \\
\text { squares }\end{array}$ & $d f$ & $\begin{array}{c}\text { Mean } \\
\text { square }\end{array}$ & $F$ value & $\begin{array}{c}p \text {-value } \\
\text { Prob }>F\end{array}$ & \\
\hline Model & 3324.63 & 5 & 664.9261 & 38.9909 & $<0.0001$ & Significant \\
$P$ & 1953.125 & 1 & 1953.125 & 114.5301 & $<0.0001$ & \\
$\alpha$ & 879.9013 & 1 & 879.9013 & 51.5969 & $<0.0001$ & \\
$v$ & 277.3013 & 1 & 277.3013 & 16.2608 & 0.0020 & \\
$\alpha \times v$ & 107.1225 & 1 & 107.1225 & 6.2816 & 0.0292 & \\
$P^{2}$ & 107.1804 & 1 & 107.1804 & 6.2845 & 0.0291 & Not \\
Residual & 187.5872 & 11 & 17.0534 & & & \\
Lack of fit & 151.8792 & 7 & 21.697 & 2.4305 & 0.2043 & significant \\
Pure error & 35.708 & 4 & 8.927 & & & \\
Cor total & 3512.218 & 16 & & & & \\
\hline Note: This ANOVA resth & & & & & & \\
\hline
\end{tabular}

Note: This ANOVA result had eliminated the non-effective sources

Table 7 R-Squared values of depth of soil cutting statistics analysis

\begin{tabular}{cccc}
\hline Std. Dev. & 4.129574 & $R^{2}$ & 0.94659 \\
\hline Mean & 64.48824 & Adj $R^{2}$ & 0.922313 \\
C.V. \% & 6.403609 & Pred $R^{2}$ & 0.85508 \\
PRESS & 508.9891 & Adeq Precision & 21.47815 \\
\hline
\end{tabular}

Figure 5 showed the effect of jet impingement angle and forward speed on depth of soil cutting when waterjet pressure was $260 \mathrm{MPa}$, the value of DSC increased with increasing $\alpha$ and decreased with increasing $v$. When $v$ was $3 \mathrm{~km} / \mathrm{h}$, DSC increased from 60.3 to $88.2 \mathrm{~mm}$ while $\alpha$ increased from 30 to $90^{\circ}$; when $v$ was $5 \mathrm{~km} / \mathrm{h}$, DSC increased from 56.3 to $63.5 \mathrm{~mm}$ while $\alpha$ increased from 30 to $90^{\circ}$. A slower forward speed led to a greater increase of DSC with the increasing waterjet pressure compared with a higher speed. When $\alpha$ was $30^{\circ}$, DSC decreased from 60.3 to $56.3 \mathrm{~mm}$ while $v$ increased from 3 to $5 \mathrm{~km} / \mathrm{h}$; When $\alpha$ was $90^{\circ}$, DSC decreased from 63.5 to $88.2 \mathrm{~mm}$ while $v$ increased from 3 to $5 \mathrm{~km} / \mathrm{h}$. In other words, for the maize stalks cutting performance a vertical jet impingement angle waterjet stream with slower forward speed had greater cutting and penetration ability than a non-vertical jet impingement angle waterjet stream with faster forward speed. Cutting power density of waterjet cutting refers to the kinetic energy can be put onto per unit area ${ }^{[11,32]}$, and in this study a vertical jet impingement angle waterjet stream with slower forward speed had higher cutting power density.

\subsection{Optimization analysis and validation experiment}

To obtain the optimized operation parameters for waterjet assisted double-disc furrow opener, Design-Expert V8.0.6 was used for the optimization analysis. The no-till seeding efficiency was a priority consideration, so the forward speed was limited to between

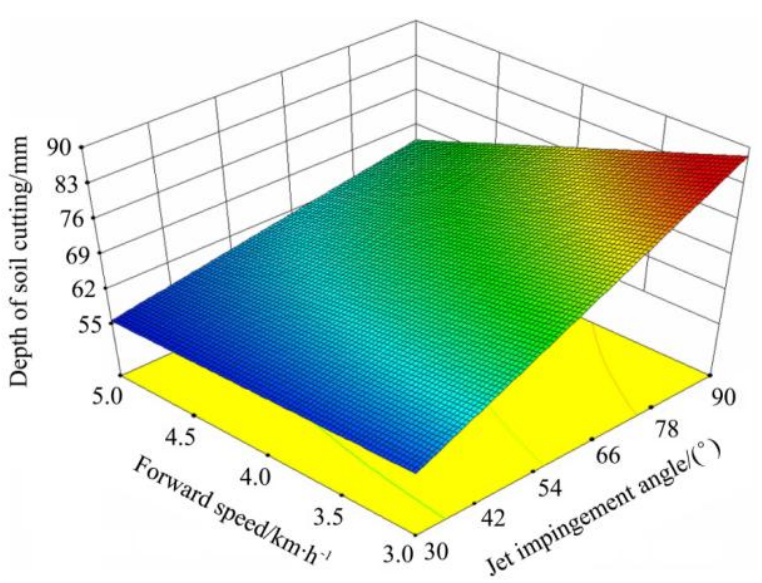

Figure 5 Effects of jet impingement angle and forward speed on depth of soil cutting (waterjet pressure $=260 \mathrm{MPa}$ )

4 to $5 \mathrm{~km} / \mathrm{h}$; For the convenience of angle adjustment, jet impingement angle ranged from $80^{\circ}$ to $90^{\circ}$; and waterjet pressure ranged from 260 to $280 \mathrm{MPa}$. According to the response surface results and the no-till seeding requirements, SCR above $95 \%$ and SCD above $40 \mathrm{~mm}$ were selected as the optimization conditions. The optimization solution indicated that when the optimized operation parameters were: waterjet pressure $=266.61$ to $280 \mathrm{MPa}$, jet impingement angle $=80.2$ to $90^{\circ}$, forward speed $=4$ to $4.42 \mathrm{~km} / \mathrm{h}$, stalks cutoff ratio ranged from $95 \%$ to $96 \%$ and depth of soil cutting ranged from 80.35 to $82.8 \mathrm{~mm}$.

According to the result of optimization analysis, the operation parameters of validation experiment were selected as: waterjet pressure was $270 \mathrm{MPa}$, jet impingement angle was $90^{\circ}$, and forward speed was $4.4 \mathrm{~km} / \mathrm{h}$. The validation experiment was conducted on the same field conditions as previous experiments and the waterjet matched the same double-disc furrow opener. Five repetitions were performed and the average values were calculated. Under the optimized operation parameters, the stalks cutoff ratio was $97.28 \%$, depth of soil cutting was $82.73 \mathrm{~mm}$, soil disturbance rate was $13.25 \%$ and blockage occurred 0 time, anti-blocking performance got a significant improvement compared with traditional no-till seeder.

\section{Conclusions}

In this study, an anti-blocking method of using ultrahigh-pressure waterjet assisted furrow opener for no-till seeder was developed, and a prototype of UHP waterjet assisted furrow opener device was designed. A statistical experiment was done to figure out the type of furrow opener which was better in coordinating with UHP waterjet. The operation parameters of waterjet were further optimized using response surface method. The main conclusions were drawn as below.

Double-disc furrow opener was able to work with UHP waterjet better than hoe type furrow opener. The soil disturbance rate of double-disc furrow opener with UHP waterjet assist was $3.15 \%$ smaller than that of hoe furrow opener. Stalks cutoff ratio and depth of soil cutting of double-disc furrow opener with UHP waterjet assist were $15.73 \%$ and $7.6 \mathrm{~mm}$ higher than that of hoe furrow opener.

Waterjet pressure, jet impingement angle and forward speed were all significantly affected stalks cutoff ratio and depth of soil cutting. A better anti-blocking performance was achieved at a higher waterjet pressure, vertical jet impingement angle and lower forward speed. To promote efficiency of agricultural production 
and operation convenience, optimization analysis was conducted and the results indicated that when waterjet pressure was 266.61 to $280 \mathrm{MPa}$, jet impingement angle was $80.2^{\circ}-90^{\circ}$ and forward speed was 4 to $4.42 \mathrm{~km} / \mathrm{h}$, stalks cutoff ratio could be above $95 \%$ and no blockage occurred. The confirmation field experiment was conducted to verify the optimization solution of RSM.

The prototype of UHP waterjet assisted furrow opener device and the research findings will offer a new approach For anti-blocking difficulty in no-till seeding and provide fundamental data for the further study, in particular, waterjet cutting utilization in agriculture.

\section{Acknowledgements}

This study was financially supported by the Special Fund for Agro-scientific Research in the Public Interest from the Ministry of Agriculture, China (Grant No. 201503136).

\section{[References]}

[1] Pittelkow C M, Liang X Q, Linquist B A, van Groenigen K J, Lee J, Lundy $\mathrm{M} \mathrm{K}$, et al. Productivity limits and potentials of the principles of conservation agriculture. Nature, 2015; 517(7534): 365-368.

[2] Wang Q, Zhu L T, Li M W, Huang D Y, Jia H L. Conservation agriculture using coulters: Effects of crop residue on working performance. Sustain., 2018; 10(11): 1-15.

[3] Rolf D, Theodor F, Amir K, Li H. Current status of adoption of no-till farming in the world and some of its main benefits. Int. J. Agric. Biol. Eng., 2010; 3(1): 1-25.

[4] Yang L, Zhang R, Gao N N, Cui T, Liu Q W, Zhang D X. Performance of no-till corn precision planter equipped with row cleaners. Int. J. Agric. Biol. Eng., 2015; 8(5): 15-25.

[5] Zeng Z, Chen Y. The performance of a fluted coulter for vertical tillage as affected by working speed. Soil Tillage Res., 2018; 175: 112-118.

[6] Smith D R, Warnemuende-Pappas E A. Vertical tillage impacts on water quality derived from rainfall simulations. Soil Tillage Res., 2015; 153: 155-160

[7] Matin M A, Fielke J M, Desbiolles J M A. Furrow parameters in rotary strip-tillage: Effect of blade geometry and rotary speed. Biosyst. Eng., 2014; 118(1): 7-15.

[8] Susuzlu T, Hoogstrate A M, Karpuschewski B. Initial research on the ultra-high pressure waterjet up to $700 \mathrm{MPa}$. J. Mater. Process. Technol., 2004; 149(1-3): 30-36.

[9] Liu X C, Liang Z W, Wen G L, Yuan X F. Waterjet machining and research developments: a review. Int. J. Adv. Manuf. Technol., 2019; 102 1257-1335.

[10] Zhao Z, Yu C, Zhong J, Huang J, Zhang X. Numerical Simulation on Continuous Non-submerged Water Jet Vibration Cleaning Process for Granular Agricultural Products. Transactions of the CSAM, 2018; 49(8): 331-337. (in Chinese)

[11] Wang L, Chen Q. Experimental study on washing cherry tomatoes with submerged jets mechanism. Transactions of the CSAE, 2007; 23(9): 86-90. (in Chinese)

[12] Wang L, Ding X. Experimental investigation of washing vegetables with submerged jets of water. Transactions of the CSAE, 2007; 23(12):
124-130. (in Chinese)

[13] Wang L. Working principle and kinematic analysis of submerged jet vegetable washer. Transactions of the CSAE, 2007; 23(6): 130-135. (in Chinese)

[14] Wang J, Yang S, Xie Q, Yi J. Experiment and operating parameter optimization using water jet technology for scallops shucking processing. Transactions of the CSAE, 2017; 33(7): 289-294. (in Chinese)

[15] Rao R V, Rai D P, Balic J. Multi-objective optimization of abrasive waterjet machining process using Jaya algorithm and PROMETHEE Method. J. Intell. Manuf., 2019; 30(5): 2101-2127.

[16] Oh T M, Cho G C. Rock cutting depth model based on kinetic energy of abrasive waterjet. $\quad$ Rock Mech. Rock Eng., 2016; 49(3): 1059-1072.

[17] Aydin G, Karakurt I, Aydiner K. Prediction of the cut depth of granitic rocks machined by abrasive waterjet (AWJ). Rock Mech. Rock Eng., 2013; 46(5): 1223-1235.

[18] Aydin G, Karakurt I, Aydiner K. Performance of abrasive waterjet in granite cutting: Influence of the textural properties. J. Mater. Civ. Eng., 2012; 24(7): 944-949.

[19] Den Dunnen S, Kraaij G, Biskup C, Kerkhoffs G M M J, Tuijthof G J M Pure waterjet drilling of articular bone: An in vitro feasibility study. Stroj. Vestnik/Journal Mech. Eng., 2013; 59(7-8): 425-432.

[20] Hu H, Li H, Wang Q, He J, Lu C, Wang Y, Wang C. Performance of waterjet on cutting maize stalks: A preliminary investigation. Int. J. Agric. Biol. Eng., 2019; 12(5): 64-70.

[21] Wang P, Zhao B, Ni H J, Li Z N, Liu Y D, Chen X Y. Research on the modulation mechanism and rock breaking efficiency of a cuttings waterjet. Energy Sci. Eng., 2019; 7(5): 1687-1704.

[22] Zhang X, Li H, Du R, Ma S, He J,Wang Q, et al. Effects of key design parameters of tine furrow opener on soil seedbed properties. Int. J. Agric. Biol. Eng., 2016; 9(3): 67-80.

[23] Chinese Standard Committee. No or little-tillage fertilizes-seeder, GB/T 20865-2017. Chinese Standard Press, China, 2017. (in Chinese).

[24] Qin K, Ding W, Ahmad F, Fang Z. Design and experimental validation of sliding knife notch-type disc opener for a no-till combine harvester cum seed drill. Int. J. Agric. Biol. Eng., 2018; 11(4): 76-85.

[25] Chaudhuri D. Performance evaluation of various types of furrow openers on seed drills - a review. J. Agric. Eng. Res., 2001; 79(2): 125-137.

[26] Solhjou A, Fielke J M, Desbiolles J M A. Soil translocation by narrow openers with various rake angles. Biosyst. Eng., 2012; 112(1): 65-73.

[27] Mabrouki T, Raissi K, Cornier A. Numerical simulation and experimental study of the interaction between a pure high-velocity waterjet and targets: Contribution to investigate the decoating process. Wear, 2000; 239(2): 260-273.

[28] Karakurt I, Aydin G, Aydiner K. An experimental study on the depth of cut of granite in abrasive waterjet cutting. Mater. Manuf. Process., 2012; 27(5): 538-544

[29] Yuvaraj N, Kumar M P. Investigation of process parameters influence in abrasive water jet cutting of D2 steel. Mater. Manuf. Process., 2017; 32(2): 151-161.

[30] Li H, Wang J. An experimental study of abrasive waterjet machining of Ti-6Al-4V. Int. J. Adv. Manuf. Technol., 2015; 81(1-4): 361-369.

[31] Thanomputra S, Kiatiwat T. Simulation study of cutting sugarcane using fine sand abrasive waterjet. Agric. Nat. Resour., 2016; 50(2): 146-153.

[32] Xue Y, Si H, Xu D, Yang Z. Experiments on the microscopic damage of coal induced by pure water jets and abrasive water jets. Powder Technol., 2018; 332(2017): 139-149. 